\title{
Adaptação de alunos ao ambiente universitário: estudo de caso em cursos de graduação da Universidade Federal do Ceará*
}

\author{
Wagner Bandeira Andriola a \\ Adriana Castro Araújo ${ }^{b}$
}

\section{Resumo}

Compreender as vivências dos alunos recém ingressos no ambiente universitário é muito relevante, pois essas experiências iniciais são vitais para a permanência e para o sucesso acadêmico. O estudo comparou a adaptação ao ambiente universitário entre estudantes (i) dos gêneros masculino e feminino; (ii) de cursos noturnos e diurnos; (iii) que exercem e não exercem atividades laborais e (iv) cotistas e não cotistas. Empregou-se uma amostra não probabilística de 832 universitários (3,2\% dos matriculados), com maioria de mulheres ( $n=422$ ou 50,7\%), com idade de 25 anos $(\mathrm{n}=211$ ou $25,3 \%)$, da área de ciências sociais aplicadas $(\mathrm{n}=318$ ou $38,2 \%)$ e do turno diurno $(n=671$ ou $80,6 \%)$, que responderam voluntariamente ao Questionário de Vivências Acadêmicas (QVA-R). Os resultados revelaram diferenças significativas entre os alunos de distintos: (i) gêneros, no tocante à Dimensão Pessoal $\left(\mathrm{F}_{[1,830]}=18,1 ; \mathrm{p}<0,001\right)$ e Dimensão Estudo $\left(\mathrm{F}_{[1,830]}=16,6\right.$; $\mathrm{p}<0,001)$; (ii) turnos, no que tange à Dimensão Pessoal $\left(\mathrm{F}_{[1,830]}=10,9 ; \mathrm{p}<0,001\right)$ e Dimensão Institucional $\left(\mathrm{F}_{[1,830]}=12,7 ; \mathrm{p}<0,001\right)$; (iii) status laboral, no que concerne à Dimensão Pessoal $\left(\mathrm{F}_{[1,830]}=7,0 ; \mathrm{p}<0,01\right)$ e à Dimensão Institucional $\left(\mathrm{F}_{[1,830]}=24,1 ; \mathrm{p}<0,001\right) \mathrm{e}$ (iv) status acadêmico (cotistas e não cotistas), no que tange à Dimensão Institucional $\left(\mathrm{F}_{[1,830]}=4,9 ; \mathrm{p}<0,05\right)$.

Palavras-chave: Ensino Superior. Avaliação Educacional. Adaptação Universitária. Vivências Acadêmicas.

\footnotetext{
* Pesquisa financiada pelo Conselho Nacional de Desenvolvimento Científico e Tecnológico, através de concessão de Bolsa de Produtividade em Pesquisa para o autor principal (Processo n 303.366/2017-6).

a Universidade Federal do Ceará, Fortaleza, CE, Brasil.

b Universidade Federal do Ceará, Fortaleza, CE, Brasil.
} 


\section{Introdução}

Nos últimos 15 anos, o Brasil testemunhou avanços substantivos no âmbito da Educação Superior, sobretudo no que se refere à adoção de políticas afirmativas (ANDRIOLA; SULIANO, 2015). À medida que as Instituições de Ensino Superior (IES) passaram a adotar tais políticas, discussões acadêmicas foram travadas, resultando em pesquisas para avaliar as repercussões dessas ações (ARAÚJO; ANDRIOLA; COELHO, 2018). Por exemplo, Ristoff (2014) estudou as alterações no perfil dos estudantes de graduação oriundas das políticas afirmativas, tais como o Programa Universidade para Todos (Prouni), o Plano Nacional de Assistência Estudantil (Pnaes) e o Fundo de Financiamento ao Estudante do Ensino Superior (Fies). O autor constatou alterações significativas no perfil dos universitários, oriundas das novas oportunidades de mobilidade social direcionadas aos trabalhadores de baixa renda, pretos, pardos e indígenas, promovidas por essas políticas.

Waltenberg e Carvalho (2012) compararam o desempenho dos alunos beneficiados por ações afirmativas com os demais alunos, demonstrando haver diferenças substantivas entre esses grupos, nos cursos com alto prestígio social, de IES privadas. Nas IES públicas, o desempenho dos cotistas foi inferior ao dos não cotistas, em todos os tipos de cursos. Consoante os autores, esse foi o preço pago pela sociedade em prol da diversidade e da equalização das oportunidades nas universidades brasileiras.

Mendes Júnior (2014) constatou resultados mais eficientes na taxa de diplomação de alunos cotistas. Porém, no que tange à evasão, os não cotistas apresentaram taxas três vezes maiores. Quanto à qualidade do aprendizado, os cotistas tiveram valores inferiores aos dos não cotistas nos cursos analisados, embora agreguem valor à universidade, pois promovem melhorias significativas nos indicadores institucionais, mormente, no que se refere à diplomação e à evasão.

Pesquisas geradoras de novas informações acerca da qualidade das vivências do alunado usuário de ações afirmativas e suas repercussões sobre o desempenho individual e institucional são relevantes (MATTA; LEBRÃO; HELENO, 2017), sobretudo estudos que abordem a adaptação discente ao ambiente universitário, compreendendo a qualidade de suas vivências, pois estas são vitais para a permanência e para o sucesso acadêmico (PASCARELLA; TERENZINI, 2005; REASON; TERENZINI; DOMINGO, 2006). Consoante Ambiel, Santos e Dalbosco (2016), Bisinoto et al. (2016), Cunha e Carrilho (2005), estudantes universitários com melhor adaptação e integração, demonstram maiores chances de crescimento intelectual, individual e acadêmico. O próximo 
tópico discorre acerca da relevância dos estudos sobre a adaptação de alunos ao ambiente universitário.

\section{Adaptação de alunos ao ambiente universitário: breve revisão temática}

O aluno universitário é submetido a exigências intrínsecas a esse nível de Ensino, tais como ajustamento às regras institucionais, adequado convívio com pares e superiores, busca por elevados desempenhos acadêmicos (OLIVEIRA et al., 2014). Nesta fase, o universitário questiona vários aspectos de sua existência, resultando em novas vivências acadêmicas (ALMEIDA; SOARES; FERREIRA, 1999). O termo vivências acadêmicas é o conjunto de situações próprias da vida universitária, ao qual estão associados os desenvolvimentos pessoal, cognitivo e social (AMBIEL; SANTOS; DALBOSCO, 2016; GRANADO et al., 2005; GUERREIRO-CASANOVA; POLYDORO, 2011; IGUE; BARIANI; MILANESI, 2008; MATTA; LEBRÃO; HELENO, 2017).

Conforme destacaram Gökel e Dağli (2017), calouros universitários podem vir a reagir de maneira heterogênea às vivências acadêmicas: alguns vão adaptar-se rápida e eficientemente; outros vão percorrer este caminho lentamente (SUEHIRO; ANDRADE, 2018); outros não se adaptarão completamente, ocasionando evasões (CARDOSO; SCHEER, 2003; OLIVEIRA; SANTOS; DIAS, 2016). Conforme Silva Filho et al. (2007), a falta de recursos financeiros e as expectativas em relação à formação são fatores que podem dificultar e desestimular o discente a priorizar a conclusão do curso (Araújo; Almeida, 2015). Relacionamentos interpessoais podem ser determinantes para a decisão de abandono do curso universitário (CUNHA; CARRILHO, 2005; MATTA; LEBRÃO; HELENO, 2017), bem como inadaptação às estratégias de Ensino (ARAÚJO, 2017; OLIVEIRA et al., 2014).

Lamas, Ambiel e Silva, (2014), Santos, Oliveira e Dias (2015) e Soares et al. (2014) enfatizam a importância da participação ativa das IES para garantir a adaptação do ingressante à vida acadêmica. Há autores que sugerem estudos para esclarecer se há diferenças na adaptação ao ambiente universitário entre os gêneros, entre os alunos de cursos noturnos e diurnos, entre os alunos que trabalham e os que não trabalham e entre as distintas áreas do conhecimento humano (BAUTH et al., 2019; SOARES et al., 2019; SOARES; MELLO, BALDEZ, 2011; SOARES; POUBE; MELLO, 2009).

Assim, com base no exposto, delineou-se investigação para comparar a adaptação ao ambiente universitário entre estudantes de cursos noturnos e diurnos; entre 
os que exercem atividades laborais e aqueles que não a exercem; entre cotistas e não cotistas; entre os gêneros masculino e feminino. Ademais, objetivou-se determinar a validade fatorial e a consistência interna do QVA-R.

\section{Metodologia}

Face à natureza da investigação, empregou-se o método ex-post facto (BISQUERRA ALZINA, 2004), também conhecido como método estatístico (GIL, 1999) ou correlacional (KERLINGER; LEE, 2002).

\subsection{Lócus de pesquisa}

O estudo foi desenvolvido com alunos regularmente matriculados em cursos de graduação da Universidade Federal do Ceará (UFC), nos três campi de Fortaleza.

\subsection{Universo e amostras de alunos e de cursos}

Participaram 832 sujeitos que constituíram amostra de 3,2\% dentre os alunos regularmente matriculados $(\mathrm{N}=20.000)$ em 33 cursos de graduação (amostra de $38,4 \%$ considerando o universo de 86 cursos nos três campi da UFC em Fortaleza).

\subsection{Instrumento}

O Questionário de Vivências Acadêmicas (QVA-R) foi usado para avaliar a percepção dos estudantes em relação às suas experiências acadêmicas (ALMEIDA; SOARES; FERREIRA, 2002). O referido instrumento é composto por cinco dimensões, a saber:

- Pessoal e emocional: faz referência às percepções individuais de bem-estar pessoal (físico e psicológico), autoconfiança, otimismo, equilíbrio emocional;

- Institucional: faz menção à percepção individual e a sentimentos em relação à qualidade do curso e da IES; da qualidade das estruturas de apoio à formação universitária; do interesse de prosseguir a formação naquele curso e concluí-la de forma exitosa;

- Interpessoal: refere-se às percepções acerca das relações com pares e professores; dos vínculos pessoais (amizades) estabelecidos no âmbito do curso e da IES; do envolvimento em atividades extracurriculares (reuniões científicas, congressos, simpósios, encontros universitários etc.); da capacidade para buscar ajuda; 
- Curso ou carreira profissional: diz respeito às percepções sobre a adaptação ao curso; as repercussões no tocante à qualidade do aprendizado individual; as perspectivas de exercício profissional; a satisfação com a formação e com o curso e

- Estudo: direciona-se às percepções das competências individuais; dos hábitos e das rotinas de estudo; do planejamento e da gestão de tempo; do uso de setores (por exemplo, biblioteca) e de recursos universitários (por exemplo, tecnologia da informação e da comunicação) para adensar o aprendizado; da preparação para exames, para estágios e para concursos.

O QVA-R é composto por 55 assertivas com escala de respostas do tipo Likert variando de 1 (totalmente em desacordo) a 4 (totalmente de acordo).

\subsection{Procedimento para a coleta dos dados}

Os alunos preencheram o QVA-R durante as aulas, após prévio contato dos auxiliares de pesquisa com as coordenações de curso e com os professores.

\section{Principais resultados}

\subsection{Análise dos Parâmetros Métricos do QVA-R}

Para identificar a estrutura fatorial, procedeu-se à verificação dos pressupostos básicos, dentre os quais, a adequação da matriz de dados originais, através do Teste de Esfericidade de Bartlett e do Teste Kayser-Meyer-Olkin (KMO), conforme a Tabela 1 .

Tabela 1 - Resultados dos Testes KMO e Bartlett

\begin{tabular}{lcc}
\hline \multicolumn{3}{c}{ Medida Kaiser-Meyer-Olkin (KMO) $=\mathbf{0 , 9 1 3}$} \\
\hline & $\chi^{2}$ & $21.162,863$ \\
Teste de Esfericidade de Bartlett & gl & 1.485 \\
& Sig. & 0,000 \\
\hline
\end{tabular}

Fonte: Pesquisa direta (2018)

Pode-se proceder à identificação da estrutura fatorial dos dados resultantes da aplicação da QVA-R, posto a significância do Teste KMO = 0,91 (valor muito 
próximo de 1,0) e do Teste de Bartlett $\left(\chi^{2}=21.162,86 ; \mathrm{p}<0,01\right)$ para verificar a adequação da amostra. Em seguida, identificou-se a estrutura fatorial da QVA-R através da Extração dos Componentes Principais (Principal Components), conforme a Figura 1.

Figura 1 - Componentes Identificados do QVA-R

Gráfico de sedimentação

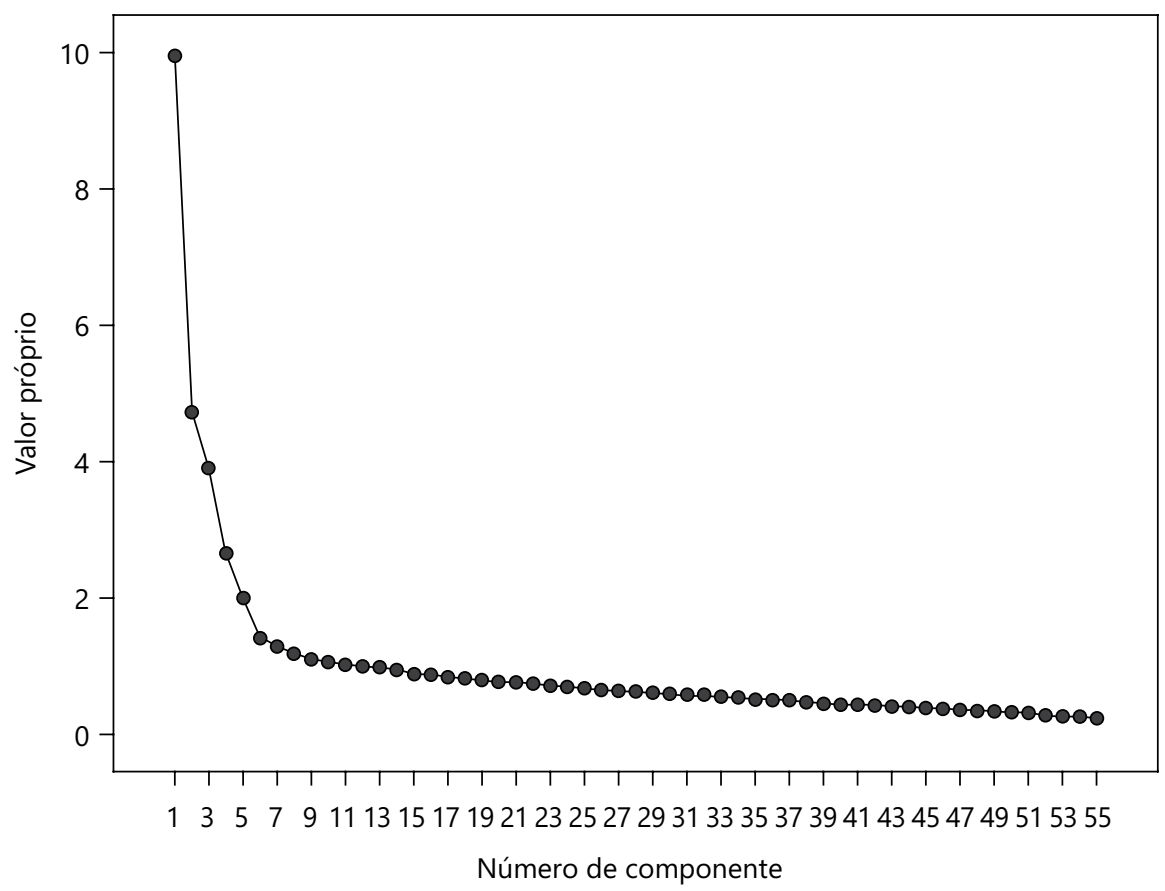

Fonte: Pesquisa direta (2018)

Conforme a composição teórica da QVA-R, há que serem extraídas cinco componentes associadas às vivências universitárias, quais sejam: pessoal e emocional; institucional; interpessoal; curso ou carreira profissional e estudo. Na Figura 1, identifica-se que a estrutura fatorial compõe-se de cinco componentes, cujos autovalores (eigenvalues) são superiores a 2,0, corroborando a estrutura teorizada para o QVA-R. Para se averiguar a relevância desses cinco componentes, procedeu-se à análise da proporção de variância explicada por cada um deles, conforme a Tabela 2. 
Tabela 2 - Resultados do uso do Método de Extração de Componentes Principais (PC)

\begin{tabular}{lccc}
\hline \multicolumn{4}{c}{ Componentes Extraídos } \\
\hline Componente & Autovalor & \% de variância & \% acumulada \\
\hline 01 & 9,957 & 18,103 & 18,103 \\
02 & 4,724 & 8,588 & 26,692 \\
03 & 3,903 & 7,096 & 33,788 \\
04 & 2,653 & 4,824 & 38,611 \\
05 & 2,009 & 3,653 & 42,265 \\
\hline
\end{tabular}

Fonte: Pesquisa direta (2018)

As cinco componentes extraídas conseguiram explicar, conjuntamente, 42,3\% da variância total, proporção bastante relevante e significativa para pesquisas educacionais. A fase seguinte consistiu em identificar a saturação de cada um dos 55 itens na componente específica da qual fazem parte, através das respectivas cargas fatoriais, adotando-se como critério delimitador o valor mínimo 0,30 (GLASS; STANLEY, 1970). Assim, itens com Cargas Fatoriais inferiores a 0,30 foram automaticamente retirados do QVA-R, conforme as informações da Tabela 3 .

Tabela 3 - Cargas Fatoriais dos 55 itens nas Cinco Componentes do QVA-R

\begin{tabular}{lccccc}
\hline \multirow{7}{*}{ Item } & \multicolumn{5}{c}{ Cargas Fatoriais dos Itens } \\
\cline { 2 - 6 } & $\begin{array}{c}\text { Componente } \\
\mathbf{1}\end{array}$ & $\begin{array}{c}\text { Componente } \\
\mathbf{2}\end{array}$ & $\begin{array}{c}\text { Componente } \\
\mathbf{3}\end{array}$ & $\begin{array}{c}\text { Componente } \\
\mathbf{4}\end{array}$ & $\begin{array}{c}\text { Componente } \\
\mathbf{5}\end{array}$ \\
\hline 1 & 0,408 & - & - & - & - \\
2 & 0,474 & - & - & - & - \\
3 & 0,613 & - & - & - & - \\
4 & 0,618 & - & - & - & - \\
5 & 0,501 & - & - & - & - \\
6 & 0,547 & - & - & - & - \\
7 & 0,318 & - & - & - & - \\
8 & 0,429 & - & - & - & - \\
9 & 0,471 & - & - & - & - \\
10 & 0,486 & - & - & - & - \\
11 & 0,550 & - & - & - & - \\
12 & 0,417 & - & - & - & - \\
\hline
\end{tabular}


continuação

\begin{tabular}{|c|c|c|c|c|c|}
\hline \multirow[b]{2}{*}{ Item } & \multicolumn{5}{|c|}{ Cargas Fatoriais dos Itens } \\
\hline & $\begin{array}{c}\text { Componente } \\
1\end{array}$ & $\begin{array}{c}\text { Componente } \\
2\end{array}$ & $\begin{array}{c}\text { Componente } \\
3\end{array}$ & $\begin{array}{c}\text { Componente } \\
4\end{array}$ & $\begin{array}{c}\text { Componente } \\
5\end{array}$ \\
\hline 13 & 0,450 & - & - & - & - \\
\hline 14 & 0,439 & - & - & - & - \\
\hline 15 & - & 0,325 & - & - & - \\
\hline 16 & - & 0,394 & - & - & - \\
\hline 17 & - & $0,225^{\star}$ & - & - & - \\
\hline 18 & - & 0,369 & - & - & - \\
\hline 19 & - & 0,327 & - & - & - \\
\hline 20 & - & $0,149^{*}$ & - & - & - \\
\hline 21 & - & $0,179^{\star}$ & - & - & - \\
\hline 22 & - & $0,137^{\star}$ & - & - & - \\
\hline 23 & - & - & 0,488 & - & - \\
\hline 24 & - & - & 0,306 & - & - \\
\hline 25 & - & - & 0,352 & - & - \\
\hline 26 & - & - & 0,421 & - & - \\
\hline 27 & - & - & $0,279 *$ & - & - \\
\hline 28 & - & - & 0,362 & - & - \\
\hline 29 & - & - & 0,383 & - & - \\
\hline 30 & - & - & 0,394 & - & - \\
\hline 31 & - & - & 0,297 & - & - \\
\hline 32 & - & - & $0,205^{*}$ & - & - \\
\hline 33 & - & - & 0,341 & - & - \\
\hline 34 & - & - & 0,437 & - & - \\
\hline 35 & - & - & - & 0,561 & - \\
\hline 36 & - & - & - & 0,506 & - \\
\hline 37 & - & - & - & 0,621 & - \\
\hline 38 & - & - & - & 0,576 & - \\
\hline 39 & - & - & - & 0,651 & - \\
\hline 40 & - & - & - & 0,641 & - \\
\hline 41 & - & - & - & 0,556 & - \\
\hline 42 & - & - & - & 0,334 & - \\
\hline 43 & - & - & - & 0,489 & - \\
\hline
\end{tabular}


continuação

\begin{tabular}{lccccc}
\hline & \multicolumn{5}{c}{ Cargas Fatoriais dos Itens } \\
\cline { 2 - 6 } Item & Componente & Componente & Componente & Componente & Componente \\
& $\mathbf{1}$ & $\mathbf{2}$ & $\mathbf{3}$ & $\mathbf{4}$ & $\mathbf{5}$ \\
\hline 44 & - & - & - & 0,340 & - \\
45 & - & - & - & 0,349 & - \\
46 & - & - & - & 0,377 & - \\
47 & - & - & - & - & 0,448 \\
48 & - & - & - & - & $0,271^{*}$ \\
49 & - & - & - & - & 0,422 \\
50 & - & - & - & - & 0,460 \\
51 & - & - & - & - & $0,272^{*}$ \\
52 & - & - & - & - & 0,480 \\
53 & - & - & - & - & 0,365 \\
54 & - & - & - & - & 0,396 \\
55 & - & - & & & $0,105^{*}$ \\
\hline
\end{tabular}

Fonte: Pesquisa direta (2018)

* Itens retirados do QVA-R

As componentes 1 (Dimensão Pessoal e Emocional) e 4 (Dimensão Curso ou Carreira Profissional) possuem itens com saturações superiores a 0,30 implicando em adequação e aderência dos conteúdos mensurados por estes. Não obstante, a componente 2 (Dimensão Institucional) perdeu quatro itens; a componente 3 (Dimensão Interpessoal) perdeu dois itens; a componente 5 (Dimensão Estudo) perdeu três itens.

Posteriormente, cada uma das cinco componentes foi identificada e conceituada, a partir de análise semântica dos conteúdos dos itens, sendo determinada a consistência interna de cada uma delas, por meio do Alfa de Cronbach, conforme a Tabela 4.

Tabela 4 - Descrição das Cinco Componentes do QVA-R e respectivos Alfas de Cronbach

\begin{tabular}{lcccc}
\hline $\begin{array}{l}\text { Componente 1 } \\
\text { (Pessoal e } \\
\text { Emocional) }\end{array}$ & $\begin{array}{c}\text { Componente 2 } \\
\text { (Institucional) }\end{array}$ & $\begin{array}{c}\text { Componente 3 } \\
\text { (Interpessoal) }\end{array}$ & $\begin{array}{c}\text { Componente 4 } \\
\text { (Curso ou Carreira } \\
\text { Profissional) }\end{array}$ & $\begin{array}{c}\text { Componente 5 } \\
\text { (Estudo) }\end{array}$ \\
\hline $\mathrm{N}^{\circ}$ de itens $=14$ & $\mathrm{~N}^{\circ}$ de itens $=5$ & $\mathrm{~N}^{\circ}$ de itens $=10$ & $\mathrm{~N}^{\circ}$ de itens $=12$ & $\mathrm{~N}^{\circ}$ de itens = 8 \\
$\alpha=0,89$ & $\alpha=0,70$ & $\alpha=0,86$ & $\alpha=0,87$ & $\alpha=0,79$ \\
\hline
\end{tabular}

Fonte: Pesquisa direta (2018) 
A etapa seguinte consistiu na análise comparativa entre universitários de cursos noturnos e diurnos; entre os que exercem atividades laborais e aqueles que não exercem; entre cotistas e não cotistas e entre os gêneros masculino e feminino.

\subsection{Análise comparativa dos alunos de cursos diurnos e noturnos}

A maioria dos alunos vinculava-se a cursos diurnos $(n=671$ ou $80,6 \%)$. No que tange ao gênero, a maioria dos alunos dos cursos diurnos foi formada por homens ( $\mathrm{n}=341$ ou 50,8\%), enquanto, entre os aprendizes dos cursos noturnos $(\mathrm{n}=162)$, a maior parte foi composta por mulheres $(\mathrm{n}=92$ ou $56,8 \%)$. A maioria dos alunos de cursos diurnos não trabalham ( $\mathrm{n}=542$ ou 80,8\%), enquanto, entre os universitários dos cursos noturnos, a maioria trabalha $(\mathrm{n}=101$ ou $62,3 \%)$.

No que se refere à adaptação dos dois grupos de alunos, foram obtidos os resultados retratados na Tabela 5.

Tabela 5 - Resultado do Teste ANOVA para comparação entre alunos matriculados em cursos diurnos e noturnos

\begin{tabular}{lcccccc}
\hline $\begin{array}{l}\text { Dimensões } \\
\text { do QVA-R }\end{array}$ & Variâncias & $\begin{array}{c}\text { Soma dos } \\
\text { quadrados }\end{array}$ & gl & $\begin{array}{c}\text { Quadrados } \\
\text { médios }\end{array}$ & F & p \\
\hline Pessoal e & Entre grupos & 742,309 & 1 & 742,309 & 10,940 & 0,001 \\
Emocional & Intra grupos & $56.318,844$ & 830 & 67,854 & - & - \\
& Total & $57.061,153$ & 831 & & - & - \\
& Entre grupos & 156,733 & 1 & 156,733 & 12,655 & 0,000 \\
Institucional & Intra grupos & $10.254,531$ & 828 & 12,385 & - & - \\
& Total & $10.411,264$ & 829 & & - & - \\
Interpessoal & Intra grupos & $37.581,423$ & 830 & 45,279 & - & - \\
& Total & $37.584,239$ & 831 & & - & - \\
Curso ou & Entre grupos & 18,246 & 1 & 18,246 & 0,311 & 0,577 \\
Carreira & Intra grupos & $48.633,831$ & 830 & 58,595 & - & - \\
Profissional & Total & $48.652,077$ & 831 & & - & - \\
& Entre grupos & 0,060 & 1 & 0,060 & 0,003 & 0,957 \\
& Intra grupos & $17.104,897$ & 830 & 20,608 & - & - \\
Estudo & Total & $17.104,957$ & 831 & & - & - \\
\hline
\end{tabular}

Fonte: Pesquisa direta (2018) 
O Teste ANOVA detectou diferenças significativas entre alunos dos cursos diurnos e noturnos, no que se refere às Dimensão Pessoal e Emocional $\left(\mathrm{F}_{[1,831]}=10,9\right.$; $\mathrm{p}<0,001)$ e à Dimensão Institucional $\left(\mathrm{F}_{[1,829]}=12,7 ; \mathrm{p}<0,001\right)$. Nas demais dimensões, as diferenças não foram significativas $(\mathrm{p}>0,01)$.

A pontuação média dos alunos dos cursos diurnos na Dimensão Pessoal e Emocional obteve valor $36,7(\mathrm{dp}=8,1)$, enquanto a pontuação média dos alunos dos cursos noturnos resultou em $34,3(\mathrm{dp}=8,7)$. A maior pontuação dos alunos dos cursos diurnos indica que estes têm percepções individuais negativas de bem-estar pessoal, social e emocional, especialmente no tocante aos aspectos físico e emocional. Esses aparentam estar mais estressados (física e emocionalmente) do que seus colegas dos cursos noturnos. Resultados similares foram encontrados por Cestari et al. (2017), Mota et al. (2016) e Rios (2006), para os quais, ter o tempo preenchido por inúmeras atividades acadêmicas, como é o caso dos universitários de cursos diurnos, diminui as chances de estes conseguirem trabalhar e ter independência financeira, aspectos considerados como potenciais estressores.

No que se refere à pontuação média dos alunos na Dimensão Institucional, os aprendizes dos cursos diurnos obtiveram $23,9(\mathrm{dp}=3,5)$, enquanto os alunos dos cursos noturnos obtiveram 25,0 (dp = 3,5). A maior pontuação dos alunos dos cursos noturnos indica percepção mais positiva em relação à qualidade do curso e da IES, à qualidade das estruturas de apoio à formação e ao interesse em prosseguir no curso para concluí-lo de com êxito.

Esses resultados corroboram os obtidos por Maranhão e Veras (2017), além de reforçar as opiniões de Terribili Filho e Nery (2009), bem como as de Lamers, Santos e Toassi (2017), para quem as oportunidades concedidas aos alunos de cursos noturnos permitem-lhes enxergar o potencial da formação superior, maximizando aspectos positivos e minimizando dificuldades e obstáculos, comumente encontrados nesses cursos. Por outro lado, Soares et al. (2019) asseveraram que alunos de IES públicas apresentam vivências acadêmicas mais elaboradas, ocasionando melhor adaptação do que alunos de IES privadas.

\subsection{Comparação entre status laboral}

A maioria dos alunos não exerce atividade laboral $(n=603$ ou 72,4\%). Porém, enquanto a maioria dos alunos de cursos diurnos não trabalha ( $\mathrm{n}=542$ ou $80,8 \%)$, a maioria dos cursos noturnos o faz $(\mathrm{n}=101$ ou $62,3 \%)$. No que se refere à adaptação desses alunos ao ambiente universitário, foram obtidos resultados presentes na Tabela 6 . 
Tabela 6 - Resultado do Teste ANOVA para comparar alunos que trabalham com os que não trabalham

\begin{tabular}{lcccccc}
\hline $\begin{array}{l}\text { Dimensões } \\
\text { do QVA-R }\end{array}$ & Variâncias & $\begin{array}{c}\text { Soma dos } \\
\text { quadrados }\end{array}$ & gl & $\begin{array}{c}\text { Quadrados } \\
\text { médios }\end{array}$ & F & p \\
\hline Pessoal e & Entre grupos & 477,180 & 1 & 477,180 & 7,000 & 0,008 \\
Emocional & Intra grupos & $56.583,972$ & 830 & 68,173 & - & - \\
& Total & $57.061,153$ & 831 & - & - & - \\
& Entre grupos & 294,446 & 1 & 294,446 & 24,099 & 0,000 \\
Institucional & Intra grupos & $10.116,818$ & 828 & 12,218 & - & - \\
& Total & $10.411,264$ & 829 & - & - & - \\
& Entre grupos & 42,564 & 1 & 42,564 & 0,941 & 0,332 \\
Interpessoal & Intra grupos & $37.541,676$ & 830 & 45,231 & - & - \\
& Total & $37.584,239$ & 831 & - & - & - \\
Curso ou & Entre grupos & 135,584 & 1 & 135,584 & 2,320 & 0,128 \\
Carreira & Intra grupos & $48.516,493$ & 830 & 58,454 & - & - \\
Profissional & Total & $48.652,077$ & 831 & - & - & - \\
& Entre grupos & 9,299 & 1 & 9,299 & 0,451 & 0,502 \\
Estudo & Intra grupos & $17.095,657$ & 830 & 20,597 & - & - \\
& Total & $17.104,957$ & 831 & - & - & - \\
\hline
\end{tabular}

Fonte: Pesquisa direta (2018)

O Teste ANOVA detectou diferenças significativas entre alunos que trabalham e que não trabalham, no que se refere à Dimensão Pessoal e Emocional $\left(\mathrm{F}_{[1,831]}=7,0\right.$; $\mathrm{p}<0,01)$ e à Dimensão Institucional $\left(\mathrm{F}_{[1,829]}=24,1 ; \mathrm{p}<0,001\right)$. Nas demais dimensões as diferenças não foram significativas $(\mathrm{p}>0,01)$.

A pontuação média na Dimensão Pessoal e Emocional dentre os que trabalham foi $35,0(\mathrm{dp}=8,9)$, enquanto a pontuação média dos alunos que não trabalham resultou em $36,7(\mathrm{dp}=8,0)$. A maior pontuação dos alunos que não trabalham revela que esses têm percepções individuais negativas de bem-estar pessoal, social e emocional, em especial, no tocante aos aspectos físico e psicológico. Esses alunos aparentam estar mais estressados (física e emocionalmente) do que os seus colegas que trabalham. Sob a ótica de Mota et al. (2016), esse cenário explica as diminutas chances desses estudantes conseguir trabalho e obter independência financeira, aumentando a probabilidade de surgimento de potenciais estressores. Paradoxalmente, conforme Mondardo e Pedon (2005), a maioria dos estudantes que não trabalham é composta por indivíduos solteiros e que não têm filhos, aspectos 
favoráveis ao rendimento acadêmico satisfatório, ampliando a probabilidade de permanência proveitosa no curso e na IES.

No que se refere à pontuação média na Dimensão Institucional, os aprendizes que trabalham obtiveram $25,1(\mathrm{dp}=3,5)$, enquanto os que não trabalham, $23,7(\mathrm{dp}=3,5)$. A maior pontuação dos que trabalham indica percepção individual mais positiva em relação à qualidade do curso, da IES, das estruturas de apoio à formação e ao interesse em concluir os estudos universitários. Estes resultados corroboram os estudos de Mondardo e Pedon (2005), Schleich (2006), Suheiro e Andrade (2018), que apontaram que a concomitância entre estudar e trabalhar não dificulta o envolvimento com as atividades acadêmicas exigidas durante a formação universitária.

\subsection{Comparação entre o status acadêmico}

No tocante ao status acadêmico, os grupos foram formados por alunos cotistas e alunos não cotistas. Dentre os cotistas, a maioria é do gênero masculino e ( $\mathrm{n}=200$ ou $52,8 \%)$, não exerce atividade laboral $(\mathrm{n}=269$ ou $71 \%)$, estuda em cursos diurnos $(\mathrm{n}=301$ ou 79,4\%) e tem idade média de 21,4 $(\mathrm{dp}=5,4)$. Dentre os alunos não cotistas, a maioria é do gênero feminino e ( $\mathrm{n}=243$ ou 53,5\%), não exerce atividade laboral $(\mathrm{n}=334$ ou $73,6 \%)$, estuda em cursos diurnos $(\mathrm{n}=370$ ou $81,5 \%)$ e tem idade média de $21,6(\mathrm{dp}=5,7)$. A Tabela 7 contém dados da adaptação universitária desses alunos.

Tabela 7 - Resultado do Teste ANOVA para comparação entre alunos cotistas e não cotistas

\begin{tabular}{lcccccc}
\hline $\begin{array}{l}\text { Dimensões } \\
\text { do QVA-R }\end{array}$ & Variâncias & $\begin{array}{c}\text { Soma dos } \\
\text { quadrados }\end{array}$ & gl & $\begin{array}{c}\text { Quadrados } \\
\text { médios }\end{array}$ & F & p \\
\hline Pessoal e & Entre grupos & 13,734 & 1 & 13,734 & 0,200 & 0,655 \\
Emocional & Intra grupos & $57.047,419$ & 830 & 68,732 & - & - \\
& Total & $57.061,153$ & 831 & - & - & - \\
& Entre grupos & 61,566 & 1 & 61,566 & 4,925 & 0,027 \\
Institucional & Intra grupos & $10.349,698$ & 828 & 12,500 & - & - \\
& Total & $10.411,264$ & 829 & - & - & - \\
& Entre grupos & 67,063 & 1 & 67,063 & 1,484 & 0,224 \\
Interpessoal & Intra grupos & $37.517,176$ & 830 & 45,201 & - & - \\
& Total & $37.584,239$ & 831 & - & - & - \\
\hline
\end{tabular}


continuação

\begin{tabular}{lcccccc}
\hline $\begin{array}{l}\text { Dimensões } \\
\text { do QVA-R }\end{array}$ & Variâncias & $\begin{array}{c}\text { Soma dos } \\
\text { quadrados }\end{array}$ & gl & $\begin{array}{c}\text { Quadrados } \\
\text { médios }\end{array}$ & F & p \\
\hline Curso ou & Entre grupos & 91,225 & 1 & 91,225 & 1,559 & 0,212 \\
Carreira & Intra grupos & $48.560,852$ & 830 & 58,507 & - & - \\
Profissional & Total & $48.652,077$ & 831 & - & - & - \\
& Entre grupos & 7,815 & 1 & 7,815 & 0,379 & 0,538 \\
Estudo & Intra grupos & $17.097,142$ & 830 & 20,599 & - & - \\
& Total & $17.104,957$ & 831 & - & - & - \\
\hline
\end{tabular}

Fonte: Pesquisa direta (2018)

Detectaram-se diferenças significativas entre cotistas e não cotistas, no que se refere à Dimensão Institucional $\left(\mathrm{F}_{[1,831]}=4,9 ; \mathrm{p}<0,05\right)$, porém, nas demais dimensões não foram significativas $(p>0,01)$. Nesta Dimensão específica, os cotistas obtiveram valor médio 24,4 $(\mathrm{dp}=3,5)$, enquanto os não cotistas, $23,8(\mathrm{dp}=3,6)$. A maior pontuação dos cotistas indica percepção individual mais positiva em relação à qualidade do curso, da IES, das estruturas de apoio à formação universitária e ao interesse em concluí-la de forma exitosa. Tal resultado corrobora os achados de Lemos (2017) e de Santos (2013), que apontaram que cotistas sentem-se mais satisfeitos com a formação quando se percebem integrados ao ambiente institucional e quando amparados pela IES. Não obstante, Piotto (2010) ponderou que a qualidade da interação entre alunos cotistas e não cotistas também depende de aspectos intrínsecos a esses (história de vida e expectativas sociais), além da dimensão institucional. Lemos (2017) observou que alunos de Medicina da Universidade Federal do Pará (UFPA) relataram ter havido clima tenso em sala de aula, especialmente, no início da formação acadêmica. Porém, à medida que cotistas passaram a ter o rendimento igual aos não cotistas, a aproximação entre ambos foi facilitada.

\subsection{Comparação entre os gêneros}

No que diz respeito aos gêneros, foram obtidos os resultados da Tabela 8 .

Tabela 8 - Resultado do Teste ANOVA para comparação entre alunos do gênero masculino e feminino

\begin{tabular}{lcccccc}
\hline $\begin{array}{l}\text { Dimensões } \\
\text { do QVA-R }\end{array}$ & Variâncias & $\begin{array}{c}\text { Soma dos } \\
\text { quadrados }\end{array}$ & gl & $\begin{array}{c}\text { Quadrados } \\
\text { médios }\end{array}$ & F & p \\
\hline \multirow{2}{*}{ Pessoal e } & Entre grupos & $1.217,236$ & 1 & 1217,236 & 18,092 & 0,000 \\
Emocional & Intra grupos & $55.843,917$ & 830 & 67,282 & & \\
& Total & $57.061,153$ & 831 & & & \\
\hline
\end{tabular}

continua 
continuação

\begin{tabular}{lcccccc}
\hline $\begin{array}{l}\text { Dimensões } \\
\text { do QVA-R }\end{array}$ & Variâncias & $\begin{array}{c}\text { Soma dos } \\
\text { quadrados }\end{array}$ & gl & $\begin{array}{c}\text { Quadrados } \\
\text { médios }\end{array}$ & F & p \\
\hline Institucional & Entre grupos & 5,573 & 1 & 5,573 & 0,443 & 0,506 \\
& Intra grupos & $10.405,691$ & 828 & 12,567 & & \\
& Total & $10.411,264$ & 829 & & & \\
Entre grupos & 11,891 & 1 & 11,891 & 0,263 & 0,608 \\
Interpessoal & Intra grupos & $37.572,348$ & 830 & 45,268 & & \\
Curso ou & Total & $37.584,239$ & 831 & & & \\
Carreira & Intra grupos & $48.629,652$ & 830 & 58,590 & & \\
Profissional & Total & $48.652,077$ & 831 & & & \\
& Entre grupos & 256,415 & 1 & 256,415 & 12,632 & 0,000 \\
Estudo & Intra grupos & $16.848,542$ & 830 & 20,299 & & \\
& Total & $17.104,957$ & 831 & & & \\
\hline
\end{tabular}

Fonte: Pesquisa direta (2018)

Detectaram-se diferenças significativas entre os gêneros masculino e feminino, em relação à Dimensão Pessoal e Emocional $\left(\mathrm{F}_{[1,831]}=18,1 ; \mathrm{p}<0,001\right)$ e em relação à Dimensão Estudo $\left(\mathrm{F}_{[1,831]}=12,6 ; \mathrm{p}<0,001\right)$. Nas demais dimensões, as diferenças não foram significativas $(\mathrm{p}>0,01)$.

Na Dimensão Pessoal e Emocional, os alunos do gênero masculino obtiveram valor médio $35,0(\mathrm{dp}=8,5)$, enquanto os do gênero feminino obtiveram $37,4(\mathrm{dp}=7,9)$. A maior pontuação do gênero feminino indica percepção individual negativa em relação à qualidade do curso e da IES, à qualidade das estruturas de apoio à formação universitária e ao interesse em prosseguir a formação no curso para concluí-lo de forma exitosa. Estes resultados corroboram os achados de Cunha e Carrilho (2005), que verificou que mulheres têm maior propensão à ansiedade e à depressão, além de experimentarem maior sofrimento psicológico. Cruz et al. (2018) ponderam que são esperados papéis sociais que interferem no desenvolvimento profissional das mulheres, tais como se casar e cuidar dos filhos. Esta sobrecarga de responsabilidades resulta em aumento da produção de hormônios, como cortisol e adrenalina, implicando altos níveis de exaustão emocional e aparecimento de quadros de ansiedade, de pânico e de depressão (CABRAS; MONDO, 2018; CESTARI et al., 2017). De acordo com Pinto e Amorim (2015), algumas percepções relacionadas à discriminação e aos assédios sexual e moral desmotivam as mulheres no início de carreira universitária, 
ocasionando estresse. Moraes (2016) e Porto e Soares (2017) arrematam asseverando que a formação universitária feminina apresenta-se permeada por valores e preconceitos, que reafirmam as desigualdades entre gêneros.

No que tange à Dimensão Estudo, os homens obtiveram valor médio 22,6 (dp = 4,7), enquanto as mulheres, 23,7 (dp = 4,3). A maior pontuação das mulheres indicou percepção mais positiva acerca das competências individuais; dos hábitos de estudo; da gestão de tempo acadêmico; do uso de setores universitários e de recursos com o fito de aquilatar o aprendizado. Esses resultados corroboram as opiniões de Anjos e Silva (2017), Cunha (2004), Noronha, Barros e Nunes (2009) e Wilson et al. (1996), para os quais as mulheres são mais competentes e sistemáticas com estudo; revelam-se mais organizadas no planejamento e no desenvolvimento dos trabalhos acadêmicos; desempenham com mais eficácia as tarefas que lhes são exigidas e revelam maior assiduidade às aulas.

\section{Conclusões e encaminhamentos}

Para muitos estudantes, a mudança do Ensino Médio para o Superior pode ser positiva e emocionante, pois implica na efetivação de projetos individuais e profissionais. Esta fase também proporciona maior liberdade parental, estabelecimento de novos vínculos e relacionamentos interpessoais além das responsabilidades acadêmicas, que acabam contribuindo para o desenvolvimento da identidade e da autonomia.

Por outro lado, a transição do Ensino Médio para o Superior também pode ocasionar períodos estressantes e ansiogênicos. Para minimizar possíveis problemas, é importante que as IES implementem programas de intervenção psicopedagógica, com o intuito de facilitar a adaptação dos estudantes recém ingressos e reduzir os transtornos desta fase. Assim, revela-se a relevância de estudos científicos que promovam novas informações acerca da qualidade das vivências dos universitários, sobretudo entre os segmentos usuários das ações afirmativas. Obter indícios científicos em relação às repercussões da adaptação ao ambiente universitário e dos seus impactos sobre o desempenho individual e institucional, são muito relevantes, desde a perspectiva psicopedagógica, acadêmica e de gestão. Portanto, o emprego do Questionário de Vivências Acadêmicas (QVA-R), enquanto instrumento válido e confiável, permitirá diagnósticos da qualidade da adaptação dos alunos universitários em cinco dimensões: Pessoal e Emocional, Institucional, Interpessoal, Curso ou Carreira Profissional e Estudo.

No caso específico do presente estudo, os achados revelam aspectos muito relevantes e essenciais para uma gestão acadêmica responsável, assim como para 
a introdução ou para o adensamento de políticas internas de apoio pedagógico e assistencial voltada aos alunos universitários, em especial, para os calouros. Para efeito de ilustração, pode-se citar a percepção positiva dos alunos de cursos noturnos sobre a qualidade do curso e da IES, bem como sobre o interesse em prosseguir a formação até a conclusão. Esse padrão também foi observado entre os alunos que exercem funções laborais. Para estes dois substratos do alunado universitário, as políticas de assistência devem ser fortalecidas, de modo a garantirem a permanência e a conclusão exitosa dos respectivos cursos.

No que se refere aos universitários oriundos de políticas afirmativas, tais como a Lei de Cotas, detectou-se a elevada satisfação dos alunos cotistas com a sua formação acadêmica, sempre que se percebem integrados ao curso e amparados pela IES. Não obstante, a qualidade da interação entre universitários cotistas e não cotistas depende de políticas institucionais que devem estar presentes e acessíveis às demandas, como os programas voltados às ações de apoio psicológico, pedagógico, médico-odontológico e financeiro.

Finalmente, no que tange às alunas universitárias, estas lidam com uma formação eivada de obstáculos e de preconceitos, que podem vir a perpetuar desigualdades de gênero, ensejando, portanto, políticas institucionais de apoio psicológico, pedagógico e acadêmico a este segmento discente. Ainda assim, diante de tantas dificuldades, a pesquisa demonstrou que as mulheres revelam maior compromisso com a formação, com o curso, com o estudo e com o desempenho acadêmico.

Para concluir, pode-se asseverar que a pesquisa brindou importantes informações sobre a adaptação de alunos calouros ao ambiente universitário. De modo a realçar a relevância do conhecimento científico para a gestão universitária, cita-se frase atribuída ao célebre pesquisador e físico inglês, Stephen William Hawking, que asseverou: o grande inimigo da ciência não é a ignorância, mas a ilusão de se ter conhecimento. 


\section{Adaptation of students to the university environment: a case study in undergraduate courses at the Federal University of Ceará}

\section{Abstract}

Understanding the experiences of freshmen students in the university environment is very relevant, because these initial experiences are vital for permanence and academic success. The study compared the adaptation to the university environment between students (i) of the masculine and feminine genders; (ii) night and day courses; (iii) who carry out labor activities with those who do not exercise; (iv) quota holders and non-quota holders. A non-probabilistic sample of 832 university students $(3.2 \%$ of the enrolled students), with a majority of women ( $n=422$ or $50.7 \%)$, aged 25 years $(n=211$ or $25.3 \%),(n=318$ or $38.2 \%)$ and daytime $(n=671$ or $80.6 \%)$, who voluntarily answered the Questionnaire on Academic Experience (QVA-R). The results revealed significant differences among students of different: (i) genders, regarding the personal dimensions $(F[1,830]=18.1, p<0.001)$ and study $(F[1,830]=16,6 ; p<0.001)$; (ii) shifts, with respect to the personal dimensions $(F[1,830]=10.9, p<0.001)$ and institutional $(F[1,830]=12,7 ; p<0.001)$; (iii) work status, regarding the personal dimensions $(F[1,830]=7.0, p<0.01)$ and institutional $(F[1,830]=24,1 ;<0.001)$; (iv) academic status (quota holders and non-quota holders), with regard to the institutional dimension $(F[1,830]=4.9, p<0.05)$.

Keywords: Higher Education. Educational Evaluation. University Adaptation. Academic Experiences.

\section{Adaptación de estudiantes al ambiente universitario: un estudio de caso en cursos de pregrado de la Universidad Federal de Ceará}

\section{Resumen}

Es muy relevante comprender las experiencias de los estudiantes que acaban de ingresar al ámbito universitario, ya que estas experiencias iniciales son vitales para la permanencia y el éxito académico. El estudio comparó la adaptación al ambiente universitario de los estudiantes (i) de los géneros masculino y femenino; (ii) de los cursos diurnos y nocturnos; (iii) que ejercen y no ejercen actividades laborales y (iv) cotizantes y no cotizantes. Se utilizó una muestra no probabilística de 832 estudiantes universitarios $(3,2 \%$ de los matriculados), con una mayoría de mujeres $(n=422$ o 50,7\%), de 25 años $(n=211$ o $25,3 \%)$, del área de ciencias sociales aplicadas $(n=318$ o $38,2 \%)$ y del turno diurno $(n=671$ o 80,6\%), quienes voluntariamente respondieron el Cuestionario de Experiencias Académicas (QVA-R). Los resultados revelaron diferencias significativas entre estudiantes de diferentes: (i) géneros, con respecto a la Dimensión Personal $\left(F_{[1,830]}=18.1 ; p<0.001\right)$ y a la Dimensión Estudio $\left(F F_{[1,830]}=16,6 ; p<0,001\right)$; (ii) turnos, con respecto 
a la Dimensión Personal $\left(F_{[1,830]}=10,9 ; p<0,001\right)$ y a la Dimensión Institucional $\left(F_{[1,830]}=12,7 ; p<0,001\right)$; (iii) situación laboral, con respecto a la Dimensión Personal $\left(F_{[1,830]}=7.0 ; p<0.01\right)$ y a la Dimensión Institucional $\left(F_{[1,830]}=24.1 ; p<0.001\right)$ y (iv) estatus académico (estudiantes cotizantes y no cotizantes), con respecto a la Dimensión Institucional $\left(F_{[1,830]}=4.9 ; p<0.05\right)$.

Palabras clave: Educación Superior. Evaluación Educacional. Adaptación Universitaria. Experiencias Académicas. 


\section{Referências}

ALMEIDA, L. S.; SOARES, A. P.; FERREIRA, J. A. Adaptação, rendimento e desenvolvimento dos estudantes no Ensino Superior: construção/validação do Questionário de Vivências Académicas. Braga: Centro de Estudos em Educação e Psicologia (CEEP), 1999.

ALMEIDA, L. S.; SOARES, A. P.; FERREIRA, J. A. Questionário de Vivências Acadêmicas (QVA-r): avaliação do ajustamento dos estudantes universitários. Avaliação Psicológica, Coimbra, v. 1, n. 2, p. 81-93, nov. 2002.

AMBIEL, R. A. M.; SANTOS, A. A. A.; DALBOSCO, S. N. P. Motivos para a evasão, vivências acadêmicas e adaptabilidade de carreiras em universitários. Psico, Porto Alegre, v. 47, n. 4, p. 288-297, dez. 2016. https://doi.org/10.15448/1980-8623.2016.4.23872

ANDRIOLA, W. B.; SULIANO, D. C. Avaliação dos impactos sociais oriundos da interiorização da Universidade Federal do Ceará. Revista Brasileira de Estudos Pedagógicos, Brasília, v. 96, n. 243, p.282-298, maio/ago. 2015. https://doi.org/10.1590/S2176-6681/339512841

ANJOS, D. R. L.; SILVA, R. H. A. Questionário de Vivências Acadêmicas (QVA-R): avaliação de estudantes de medicina em um curso com currículo inovador. Avaliação (Campinas), v. 22, n. 1, p. 105-123, jan./abr.2017.

ARAÚJO, A. Sucesso no ensino superior: uma revisão e conceptualização. Revista de Estudios e Investigación en Psicología y Educación, Coruña, v. 4, n. 2, p. 132-141, 2017.

ARAÚJO, A.; ALMEIDA, L. S. Adaptação ao ensino superior: o papel moderador das expectativas acadêmicas. Lumen Educare, Hortolândia, v. 1, n. 1, p. 13-32, jun. 2015. https://doi.org/10.19141/2447-5432/lumen.v1.n1.p.13-32

ARAÚJO, A. C.; ANDRIOLA, W. B.; COELHO, A. A. Programa Institucional de Bolsa de Iniciação à Docência (PIBID): desempenho de bolsistas versus não bolsistas. Educação em Revista, Belo Horizonte, v. 34, e172839, 2018. https://doi.org/10.1590/0102-4698172839

BAUTH, M. F. et al. Avaliação das habilidades sociais de universitários ingressantes e concluintes. Contextos Clínicos, São Leopoldo, v. 12, n. 1, p. 104-123, jan./abr. 2019. http://dx.doi.org/10.4013/ctc.2019.121.05 
BISINOTO, C. et al. Expectativas acadêmicas dos ingressantes da universidade de Brasília: indicadores para uma política de acolhimento. In: ALMEIDA, L. S.; CASTRO, R. V. (orgs.). Ser estudante no Ensino Superior: o caso dos estudantes do $1^{\circ}$ ano. Braga: Universidade do Minho, 2016. p. 15-31.

BISQUERRA ALZINA, R. Metodología de la investigación educativa. Madrid: Editorial la Muralla, 2004.

CABRAS, C.; MONDO, M. Coping strategies, optimism, and life satisfaction among first-year university students in Italy: gender and age differences. Higher Education, [s. 1.], v. 75, n. 4, p. 643-653, Apr. 2018. https://doi.org/10.1007/s10734-017-0161-x

CARDOSO, A. T.; SHEER, A. P. Diagnóstico do acompanhamento acadêmico dos calouros de engenharia química da UFPR. In: CONGRESSO BRASILEIRO DE ENSINO DE ENGENHARIA, 31.,2003, Rio de Janeiro. Anais[...] Rio de Janeiro: IME, 2003. p. 29-32.

CESTARI, V. R. F. et al. Estresse em estudantes de enfermagem: estudo sobre vulnerabilidades sociodemográficas e acadêmicas. Acta Paulista de Enfermagem, São Paulo, v. 30, n. 2, p. 190-196, mar./abr. 2017. https://doi.org/10.1590/1982-0194201700029

CRUZ, N. G. et al. Desigualdade de gênero em empresas de auditoria externa. Revista Contabilidade, Gestão e Governança, Brasília, v. 21, n. 1, p.142-159, 2018. https://doi.org/10.21714/1984-3925_2018v21n1a8

CUNHA, S. M. A inteligência e as habilidades sociais na adaptação de alunos ao curso superior: um estudo com alunos do $1^{\circ}$ ano do Instituto Militar de Engenharia. Dissertação (Mestrado em Engenharia) - Universidade Gama Filho, Rio de Janeiro, 2004.

CUNHA, S. M.; CARRILHO, D. M. O processo de adaptação ao Ensino Superior. Psicologia Escolar e Educacional, Campinas, v. 9, n. 2, p. 215-222, dez. 2005. https://doi.org/10.1590/S1413-85572005000200004

GIL, A. C. Métodos e técnicas da pesquisa social. São Paulo: Atlas, 1999.

GLASS, G.; STANLEY, J. Statistical methods in education and psychology. Englewood Cliffs: Prentice-Hall, 1970.

GÖKEL, Ö.; DAĞLI, G. Effects of social skill training program on social skills of young people. EURASIA Journal of Mathematics, Science and Technoloy Education, London, v. 13, n. 11, p. 7365-7373, Nov. 2017. https://doi.org/10.12973/ejmste/79615 
GRANADO, J. I. F. et al. Integração académica de estudantes universitários: contributos para a adaptação e validação do QVA-r no Brasil. Psicologia e Educação, Covilhã, v. 2, n. 4, p. 31-41, dez. 2005.

GUERREIRO-CASANOVA, D. C.; POLYDORO, S. Autoeficácia e integração ao ensino superior: um estudo com estudantes de primeiro ano. Psicologia: Teoria e Prática, São Paulo, v. 13, n. 1, p. 75-88, 2011.

IGUE, E. A.; BARIANI, I. C. D.; MILANESI, P. V. B. Vivência acadêmica e expectativas de universitários ingressantes e concluintes. Psico-USF, Itatiba, v. 13, n. 2, p. 155-164, jul./dez. 2008. https://doi.org/10.1590/S1413-82712008000200003

KERLINGER, F..; LEE, H. Investigación del comportamiento: métodos de investigación en ciencias sociales. México: McGraw Hill, 2002.

LAMAS, K. C. A.; AMBIEL, R. A. M.; SILVA, B. T. L. Vivências acadêmicas e empregabilidade de universitários em final de curso. Temas em Psicologia, Ribeirão Preto, v. 22, n. 2, p. 329-340, dez. 2014. https://doi.org/10.9788/TP2014.2-05

LAMERS, J. M.; SANTOS, B. S.; TOASSI, R. F. Retenção e evasão no Ensino Superior público: estudo de caso em um curso noturno de Odontologia. Educação em Revista, Belo Horizonte, v. 33, e154730, 2017. https://doi.org/10.1590/0102-4698154730

LEMOS, I. B. Narrativas de cotistas raciais sobre suas experiências na universidade. Revista Brasileira de Educação, Rio de Janeiro, v. 22 n. 71, e227161, 2017. https://doi.org/10.1590/s1413-24782017227161

MARANHÃO, J. D.; VERAS, R. M. O ensino noturno na Universidade Federal da Bahia: percepções de estudantes. Ensaio: Avaliação de Políticas Públicas em Educação, Rio de Janeiro, v. 25, n. 96, p. 553-584, jul./set. 2017. https://doi.org/10.1590/s0104-40362017002500854

MATTA, C. M. B.; LEBRÃO, S. M. G.; HELENO, M. G. V. Adaptação, rendimento, evasão e vivências acadêmicas no ensino superior: revisão da literatura. Psicologia Escolar e Educacional, Maringá, v. 21, n. 3, p. 583-591, set./dez. 2017. https://doi.org/10.1590/2175-353920170213111118

MENDES JUNIOR, A. A. F. Uma análise da progressão dos alunos cotistas sob a primeira ação afirmativa brasileira no ensino superior: o caso da Universidade do Estado do Rio de Janeiro. Ensaio: Avaliação de Políticas Públicas em Educação, Rio de Janeiro, v. 22, n. 82, p. 31-59, jan./mar. 2014. https://doi.org/10.1590/S0104-40362014000100003 
MONDARDO, A. H.; PEDON, E. A. Estresse e desempenho acadêmico em estudantes universitários. Revista de Ciências Humanas, Frederico Westphalen, v. 6, n. 6, p. 159-180, 2005.

MORAES, A. Z. Relações de gênero e a formação de engenheiras e engenheiros. Dissertação (Mestrado em Educação) - Universidade do Sul de Santa Catarina, Tubarão, 2016.

MOTA, N. I. F. et al. Estresse entre graduandos de enfermagem de uma universidade pública. Revista Eletrônica Saúde Mental, Álcool e Drogas, Ribeirão Preto, v. 12, n. 3, p. 163-170, set. 2016. https://doi.org/10.11606/issn.1806-6976.v12i3p163-170

NORONHA, A. P. P.; BARROS, M. V. D. C.; NUNES, M. F. O. Correlações entre interesses profissionais e inteligência em adolescentes. Psicologia: Teoria e Prática, São Paulo, v. 11, p. 114-128, dez. 2009.

OLIVEIRA, C. T.; SANTOS, A. S.; DIAS, A. C. G. Expectativas de universitários sobre a universidade: sugestões para facilitar a adaptação acadêmica. Revista Brasileira de Orientação Profissional, Florianópolis, v. 17, n. 1, p. 43-53, jun. 2016.

OLIVEIRA, C. T. et al. Adaptação acadêmica e coping em estudantes universitários brasileiros: uma revisão da literatura. Revista Brasileira de Orientação Profissional, Florianópolis, v. 15, n. 2, p. 177-186, 2014.

OLIVEIRA, C. T. et al. Percepções de estudantes universitários sobre a relação professor-aluno. Psicologia Escolar e Educacional, Maringá, v. 18, n. 2, p. 239-246, maio/ago. 2014. https://doi.org/10.1590/2175-3539/2014/0182739

PASCARELLA, E.; TERENZINI, P. How college affects students: a third decade of research. San Francisco: Jossey Bass, 2005.

PINTO, E. J.; AMORIM, V. G. Gênero e educação superior: um estudo sobre as mulheres na Física. In: REUNIÃO NACIONAL DA ANPED, 37., 2015, Florianópolis. Anais[...] Rio de Janeiro: Anped, 2015. Disponíel em: http://37reuniao.anped.org.br/wp-content/uploads/2015/02/TrabalhoGT23-3778.pdf. Acesso em: 22 set. 2018.

PIOTTO, D. C. Universitários de camadas populares. Revista Brasileira de Orientação Profissional, São Paulo, v. 11, n. 2, p. 229-242, dez. 2010. 
PORTO, A. M. S.; SOARES, A. B. Diferenças entre expectativas e adaptação acadêmica de universitários de diversas áreas do conhecimento. Análise Psicológica, Lisboa, v. 34, n. 1, p. 13-24, mar. 2017.

REASON, R.; TERENZINI, P.; DOMINGO, R. First things first: developing academic competence in the first year of college. Research in Higher Education, [s. 1.], v. 47, p. 149-175, Mar. 2006. https://doi.org/10.1007/s11162-005-8884-4

RIOS, O. F. L. Níveis de stress e depressão em estudantes universitários. Dissertação (Mestrado em Psicologia Clínica) - Pontifícia Universidade Católica de São Paulo, São Paulo, 2006.

RISTOFF, D. O novo perfil do campus brasileiro: uma análise do perfil socioeconômico do estudante de graduação. Avaliação: Revista da Avaliação da Educação Superior, Campinas, v. 19, n. 3, p. 723-747, nov. 2014. https://doi.org/10.1590/S1414-40772014000300010

SANTOS, A. S.; OLIVEIRA, C. T.; DIAS, A. C. G. Características das relações dos universitários e seus pares: implicações na adaptação acadêmica. Psicologia: Teoria e Prática, São Paulo, v. 17, n. 1, p. 150-163, abr. 2015.

SANTOS, P. V. S. Adaptação à universidade dos estudantes cotistas e não cotistas: relação entre vivência acadêmica e intenção de evasão. Dissertação (Mestrado em Psicologia) - Universidade Federal da Bahia, Salvador, 2013.

SCHLEICH, A. L. R. Integração na educação superior e satisfação acadêmica de estudantes ingressantes e concluintes. Dissertação (Mestrado em Educação) - Universidade Estadual de Campinas, Campinas, 2006.

SILVA FILHO, R. L. L. et al. A evasão no ensino superior brasileiro. Cadernos de Pesquisa, São Paulo, v. 37, n. 132, p. 641-659, set./dez. 2007. https://doi.org/10.1590/S0100-15742007000300007

SOARES, A. B. et al. Comportamentos sociais acadêmicos de universitários de instituições públicas e privadas: o impacto nas vivências no ensino superior. Pesquisas e Práticas Psicossociais, São João del-Rei, v. 14, n. 1, e1783, jan./mar. 2019.

SOARES, A. B. et al. O impacto das expectativas na adaptação acadêmica dos estudantes no Ensino Superior. Psico-USF, Bragança Paulista, v. 19, n. 1, p. 49-60, jan./abr. 2014. https://doi.org/10.1590/S1413-82712014000100006 
SOARES, A. B.; MELLO, T. V. S.; BALDEZ, M. O. M. Vivências acadêmicas em estudantes universitários do Estado do Rio de Janeiro. Interação em Psicologia, Curitiba, v. 15, n. 1, p. 59-69, 2011. https://doi.org/10.5380/psi.v15i1.16049

SOARES, A. B.; POUBEL, L. N.; MELLO, T. V. S. Habilidades sociais e adaptação acadêmica: um estudo comparativo em instituições de ensino público e privado. Aletheia, Canoas, n. 29, p. 27-42, jun. 2009.

SUEHIRO, A. C. B.; ANDRADE, K. S. Satisfação com a experiência acadêmica: um estudo com universitários do primeiro ano. Psicologia em Pesquisa, Juiz de Fora, v. 12, n. 2, p. 1-10, maio/ago. 2018. htps://doi.org/10.24879/2018001200200147

TERRIBILI FILHO, A.; NERY, A. C. B. Ensino superior noturno no Brasil: história, atores e políticas. Revista Brasileira de Política e Administração da Educação, Goiânia, v. 25, n.1, p. 61-81, 2009. https://doi.org/10.21573/vol25n12009.19327

WALTENBERG, F.; CARVALHO, M. Cotas aumentam a diversidade de estudantes sem comprometer o desempenho? Sinais Sociais, Rio de Janeiro, v. 7, p. 36-77, 2012.

WILSON, J. et al. Student's quality of life after a major curriculum change. Academic Medicine, Philadelphia, v. 71, n. 10, p. 40-42, 1996.

\section{Informações sobre os autores}

Wagner Bandeira Andriola: Professor Titular. Coordenador do Mestrado Profissional em Políticas Públicas e Gestão da Educação Superior da Universidade Federal do Ceará. Pesquisador Nível 1C do Conselho Nacional de Desenvolvimento Científico e Tecnológico. Contato:w_andriola@yahoo.com

(iD) https://orcid.org/0000-0001-6459-0992

Adriana Castro Araújo: Mestra em Políticas Públicas e Gestão da Educação Superior. Pesquisadora e Doutoranda em Avaliação Educacional na Universidade Federal do Ceará. Contato: driaraujo12@gmail.com

iD https://orcid.org/0000-0001-7739-0471 